\title{
Phytopathology"
}

\section{Advances in Plant-Nematode Interactions with Emphasis on the Notorious Nematode Genus Meloidogyne}

\author{
Isgouhi Kaloshian $^{1,2, \dagger}$ and Marcella Teixeira ${ }^{1}$
}

${ }^{1}$ Department of Nematology, University of California, Riverside, CA 92521

${ }^{2}$ Institute for Integrative Genome Biology, University of California, Riverside, CA 92521

Accepted for publication 12 September 2019.

\begin{abstract}
Plant infections by plant-parasitic nematodes (PPNs) continue to be one of the major limitations in agricultural systems. Root-knot nematodes (RKNs), belonging to the genus Meloidogyne, are one of the most important groups of PPNs worldwide. Their wide host range combined with ubiquitous presence, continues to provide challenges for their control and breeding for resistance. Although resistance to RKNs has been identified, incorporation of these resistances into crops and durability of the resistance remains challenging. In addition, progress in cloning of RKN resistance genes has been dismal. Recent identification of pattern-triggered immunity in roots against nematodes, an ascaroside as a nematode-associated molecular pattern (NAMP) and the discovery of a NAMP plant receptor, provide tools and opportunities to develop durable host resistance against nematodes including RKNs.
\end{abstract}

Keyword: nematology

Plant-parasitic nematodes (PPNs) are soil dwelling animals that belong to a group of over 4,100 species (Decraemer and Hunt 2006), are able to penetrate and parasitize plants, and are responsible for \$US157 billion in crop losses annually worldwide (Abad et al. 2008). In this review, we describe recent advances in PPNs research focusing on nematode recognition and early plant responses. In addition, we highlight knowledge on disease resistance genes and mechanism of resistance to one of the notorious groups of PPNs, the root-knot nematodes (RKNs, Meloidogyne spp.).

\section{PPNS}

A common feature ubiquitous among PPNs is the specialized mouthpart or the stylet, which resembles a hypodermic needle. Nematodes use their stylets to penetrate plant roots and inject secreted effectors originating from the esophageal glands to establish parasitism on a variety of plant species (Vieira and

${ }^{\dagger}$ Corresponding author: I. Kaloshian; isgouhi.kaloshian@ucr.edu

Funding: Research in I. Kaloshian lab is funded by USDA National Institute of Food and Agriculture grants: AFRI (2017-67014-26699), USDA Hatch (1017522), and Multistate project (1018832).

The author(s) declare no conflict of interest.

(C) 2019 The American Phytopathological Society
Gleason 2019). Different modes of adaptation and parasitic behavior allow nematodes to succeed in a variety of different habitats, both above- and belowground. PPNs are divided into ectoparasites, endoparasites, and semi-endoparasites depending on their location on the host when they feed. The endoparasites are further divided into migratory and sedentary depending on their motility after initiating feeding.

Migratory endoparasites, such as the root lesion nematodes (Pratylenchus spp.), burrowing nematode (Radopholus similis), rice root nematode (Hirschmanniella oryzae), pine wilt nematode (Bursaphelenchus xylophilus), and red ring nematode (Bursaphelenchus cocophilus), are known to inflict great damage during their migration inside plant tissues and are known for causing severe necrotic symptoms. In a wide context, these nematodes can all be referred to as lesion nematodes, since they trigger the formation of lesions while migrating inside plant tissues (Fosu-Nyarko and Jones 2016). In contrast, sedentary endoparasites, as the name indicates, penetrate the host and form an intimate relationship with their host, feeding on the same site for life and becoming sessile as soon as they initiated feeding. This group includes the most intensely studied PPNs, the RKNs and cyst nematodes (CNs) of the genera Heterodera and Globodera (Jones et al. 2013). Under proper environmental conditions, their infective stage, the second-stage juvenile (J2), hatches from eggs, is attracted to and penetrates roots of hosts. While $\mathrm{CNs}$ penetrate roots at undefined locations, RKN penetrate roots mainly behind the tip, in the root elongation zone. Another distinction between RKNs and CNs is 
their mode of migration through the plant. While RKNs move intercellularly, CNs move intracellularly both with destinations toward the vascular cylinder, where they establish specialized feeding sites and become sedentary. RKNs induce the formation of giant cells, which are the outcome of cells that undergo karyokinesis without cytokinesis, resulting in hypertrophied, enlarged, multinucleated structures. CNs induce the formation of syncytia, which are also multinucleated enlarged cells formed by the degradation of the cell walls, leading to connection of adjacent cells and resulting in the multinucleated syncytium. Both types of feeding sites are nutrient sinks for the nematodes and are tightly regulated by their secreted effectors (Favery et al. 2016; Juvale and Baum 2018). The very ability to establish a permanent feeding site and manipulate it to act as a nutrient sink, shows the evolutionary complexity between these PPNs and their hosts. Once the feeding site is established, nematodes become sedentary and undergo molts to become adult. Maintenance of the feeding sites is necessary for the completion of their life cycle and producing large numbers of progeny that initiate new rounds of infection. Considering damage caused, host range and number of scientific publications, RKNs and CNs are recognized as the two most important PPN groups worldwide (Jones et al. 2013).

\section{RKN: A NOTORIOUS GENUS}

Members of the genus Meloidogyne, are the most economically harmful nematodes worldwide (Fig. 1). In addition, members of this genus with the widest host range, such as $M$. incognita and $M$. javanica, are species that reproduce asexually without undergoing meiosis. The ability of these species to adapt to and feed on a large number of plant species, from diverse taxa, suggests the existence of a large genetic diversity within these polyphagous species. However, the lack of sexual reproduction has hindered scientists in deciphering the underlying genetics of this impressive host adaptability and the ability to predict host ranges. Instead, to characterize the different populations of a certain species of this group, a race designation was implemented based on a set of host plants and specific cultivars that were initially thought to distinguish among races of the polyphagous Meloidogyne spp. (Hartman and Sasser 1985). However, over time, RKN populations were identified that did not behave as predicted in this differential host test resulting in calls for discontinuing the use of this race designation scheme (dos Santos et al. 2012; Moens et al. 2009). Although molecular markers were identified that distinguished the different RKN species, no molecular markers have been identified that distinguished among the different races within a species (Williamson and Roberts 2009). Consistent with the lack of genetic variation among the races of a single species, sequencing of genomes of eleven isolates of $M$. incognita, originating from distinct locations, host adaptation and race designation, low sequence variation was detected among these isolates/races (Koutsovoulos et al. 2019). Furthermore, the limited variation observed was not correlated with the host races. Consequently, the challenge remains as to how to predict and advise farmers on the crops, and specific cultivars, they can plant based on nematode identification. The lack of genetic variation among these races suggests a major role for the epigenome in regulating host adaptation.

\section{ATTRACTION TO THE HOST}

The first important step for the success of a parasite is finding the host. It has been long known that RKN infective stage juveniles are capable of detecting a signal gradient to find a host and to chemotax along gradients of carbon dioxide. More recently, using a transparent gel medium, Pluronic F-127, that allowed mimicking the threedimensional structure of soil, a series of elegant experiments revealed interesting RKN behavioral characteristics and allowed dissection of cues that are involved in attraction to root tips. These experiments showed that, while infective-stage juveniles from different RKN species are attracted to the plant root tip, the movement toward the tip of a common host was at different rates, indicating genetic differences in motility among PPNs (Wang et al. 2009a). In addition, $\mathrm{RKN}$ infective-stage juveniles were attracted to a low $\mathrm{pH}$ environment, measured using a $\mathrm{pH}$ gradient gel system, consistent with the known acid efflux pattern at the surface of a growing primary root (Wang et al. 2009b). Furthermore, these experiments showed that attraction to carbon dioxide, and likely other known nematode attractants, is likely indirect, and is due to acidification of solutions by these compounds and not directly by the compounds themselves. These experiments also showed that, besides a $\mathrm{pH}$ gradient, the plant hormone ethylene is involved in chemotaxis of nematodes to plant roots. However, differences in attractiveness to ethylene among different nematode species has been observed. While active ethylene signaling in Arabidopsis reduced root attractiveness to RKN and Heterodera glycines, enhanced attractiveness of $H$. schachtii to an ethylene overproducing Arabidopsis mutant or ethephon-treated Arabidopsis roots has been reported, suggesting variable responses among similar group of nematodes, albeit with different host ranges (Fudali et al. 2013; Hu et al. 2016; Kammerhofer et al. 2015; Wubben et al. 2001).

How PPNs sense and utilize plant cues is not well understood. Morphological studies of the infective-stage juveniles suggest that amphids and phasmids, chemosensory organs located in the nematode head and tail regions, respectively, are the main sensory
FIGURE 1

Tomato plants, grown in a plastic house, infected with the root-knot nematode Meloidogyne incognita.

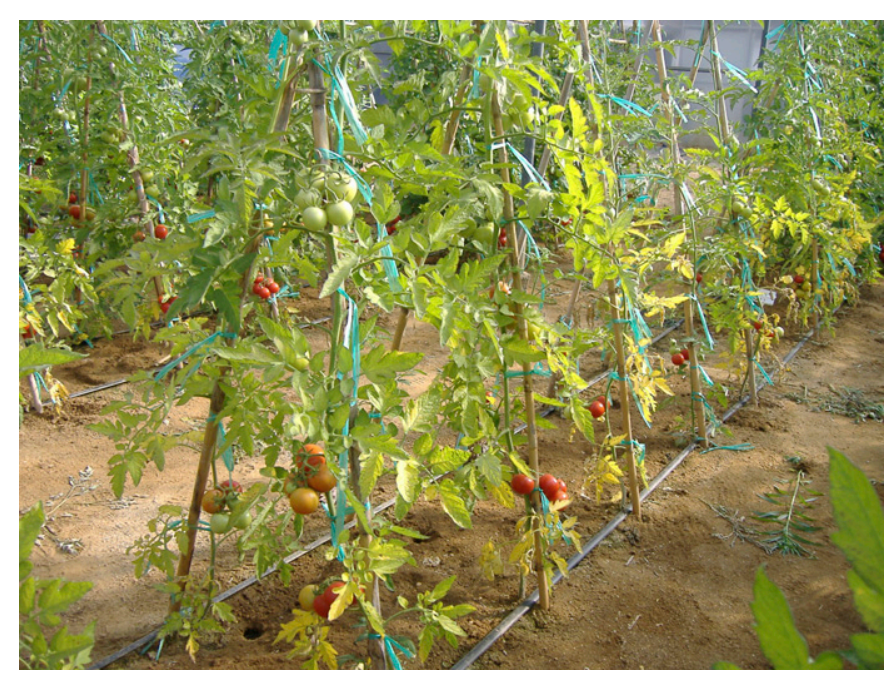


organs involved in plant host perception (Curtis et al. 2009). Consequently, interfering with chemoreception has been a means to control plant infection by PPNs and was shown to be one of the modes of actions of certain nematicides (Curtis et al. 2009).

\section{PLANT EARLY RESPONSES TO NEMATODE PENETRATION}

In recent years, the processes involved in root perception of nematodes and early responses during nematode penetration have been unveiled. It was shown that RKN and $\mathrm{CN}$ infective-stage juveniles are perceived by plant roots, during their root migration phase, similar to the perception of microbial pathogens in above ground tissues (Mendy et al. 2017; Teixeira et al. 2016). Nematode perception requires the well-characterized cell-surface localized pattern recognition coreceptor BAK1/SERK3 as SERK3 silenced tomato plants displayed enhanced susceptibility to RKN (Fig. 2) (Peng and Kaloshian 2014). BAK1 is a coreceptor of multiple microbe-associated molecular patterns (MAMPs) coordinating perception with diverse pattern-recognition receptors (PRRs) to activate pattern-triggered immunity (PTI) (Bohm et al. 2014). Enhanced susceptibility to both $\mathrm{RKN}$ and $\mathrm{CN}$ were also reported on the Arabidopsis bak1-5 mutant allele (Mendy et al. 2017; Teixeira et al. 2016). It is likely that BAK1 coordinates nematode perception through multiple PRRs similar to its role in microbial pathogen perception. Recently, a receptor-like kinase (RLK) involved in nematode-induced immune responses was shown to have similar characteristics to microbial PRRs (Mendy et al. 2017). In addition, Arabidopsis mutants of the kinase BIK1 and the double mutant of the respiratory burst NADPH oxidase (RBOH) D/F also displayed enhanced susceptibility to RKN infection, indicating that canonical PTI signaling is involved in the nematode perception (Fig. 2) (Teixeira et al. 2016).

The Arabidopsis NEMATODE-INDUCED LRR-RLK 1 (NILR1) encoding a leucine-rich repeat (LRR) serine/threonine kinase, was identified as a putative receptor of a yet unidentified nematode-associated molecular pattern (NAMP). Sequence information indicated that NILR1 has a transmembrane domain with the LRR of NILR1 localized extracellularly while the kinase domain localized intracellularly. Transient expression of NILR1 in Nicotiana benthamiana leaves indicated that NILR is localized to the plasma membrane consistent with its role as a PRR. The NILR1 transcripts were upregulated early after $H$. schachtii infection of Arabidopsis roots and the nilrl null mutants exhibited enhanced susceptibility to $H$. schachtii (Mendy et al. 2017). Interestingly, the enhanced susceptibility phenotype was also reported against $M$. incognita suggesting that NILR1 might be a receptor of a NAMP common among CNs and RKNs. Consistent with its role as a receptor and positive regulator of immunity, nilrl mutants were compromised in reactive oxygen species (ROS) burst. Arabidopsis has two NILR genes belonging to the subfamily $\mathrm{X}$ of the LRR-RLKs (Matsushima and Miyashita 2012). Unlike the majority of microbial PRRs, NILR1 is widely conserved in dicotyledonous and monocotyledonous plants (Mendy et al. 2017). The wide presence of NILR1 among susceptible plant species and/or genotypes suggests that nematodes have acquired effectors that enable them to evade PTI. However, overexpression of NILR1 may provide an opportunity to generate stable and broad-spectrum resistance against PPNs.

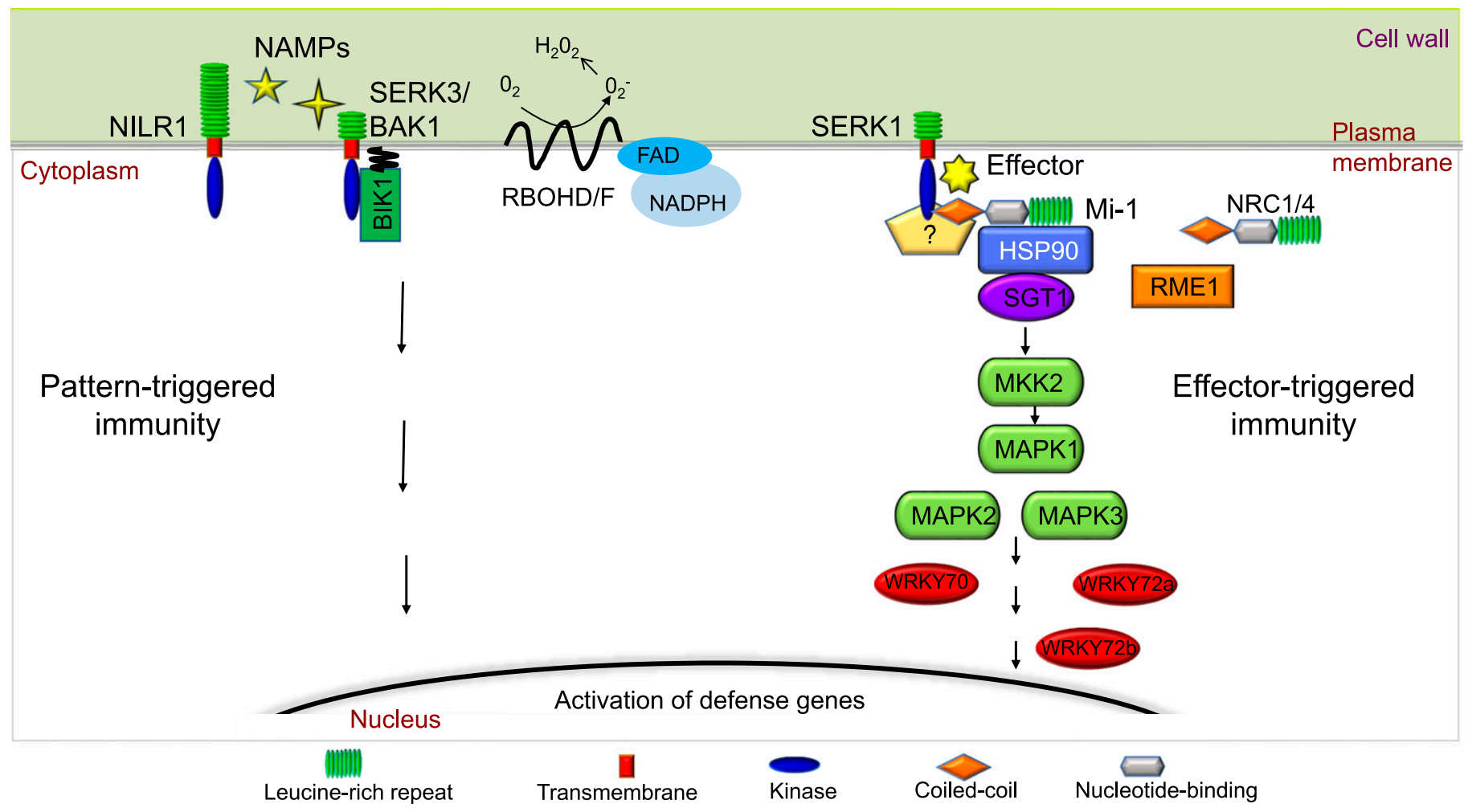

FIGURE 2

Immune receptors and defense signaling components against plant parasitic nematodes. Unknown nematode-associated molecular pattern(s) (NAMPs) is recognized by the plasma membrane localized receptor kinase NILR1 triggering pattern-triggered immunity (PTI) responses. PTI against nematode involves the membrane localized receptor-like kinase (RLK) SERK3/BAK1 and the membrane associated kinase BIK1. This recognition triggers production of reactive oxygen species by the NADPH oxidases, the RBOHD/F, which requires the coenzyme FAD. The Mi-1 resistance protein associates indirectly with the membrane localized RLK SERK1. Upon pest perception, a conformation change in the SERK1-Mi-1 complex triggers immune responses that involve HSP90, SGT1, NRC1/4, and RME1. This effector-triggered immunity response involves members of the mitogen-activated protein kinase cascades (MKK2, MAPK1-3) and WRKY transcription factors. 


\section{NAMPS}

What components of the nematodes are perceived by plant PRRs is currently of great interest. Considering nematode structure and biology, the surface coat could be an obvious source of NAMPs. Nematode cuticle is covered by a surface coat originated from the cuticle hypodermis, is covered with antigenic molecules made up of proteins and glycoproteins thought to originate from secretoryexcretory systems (Davies and Curtis 2011). The surface coat has been shown to play an important role in interactions of different nematodes with their hosts including, PPNs, entomopathogenic nematodes, and animal gastrointestinal parasites (Davies and Curtis 2011; Patel et al. 2009; Schmid-Hempel 2008). Interestingly, the surface coat is continuously shed and replaced by a new antigenic surface. It is possible therefore that proteins present in the surface coat are recognized by the host plant and is potentially the reason why it is shed by the nematode to evade recognition (De Veer et al. 2007). Additional sources of NAMPs could be extracellular secretions of glycan moieties, glycoproteins and small molecules, in addition to chitin present in the nematode eggshells and the esophageal lumen walls (Holbein et al. 2016).

The only NAMP known to date is an ascaroside. Ascarosides are glycolipids that act as dauer pheromones and aggregation and repulsion signals among nematodes. Ascarosides were first characterized as a lipid that accounted for $25 \%$ of the total lipid content of Ascaris lumbricoides, a human parasite, and are present in a wide range of nematode species, including free living and parasitic (mammal, insect and plants) nematodes (Choe et al. 2012). Their relevance in nematode biology, abundance, and conservation across taxa fits the general characteristics of a conserved signature molecule for a group organisms. Using mass spectrometry, ascaroside 18 was shown to be the most abundant ascaroside in the infective-stage juveniles of five PPN species (Manosalva et al. 2015). Consistently, exogenous application of ascaroside 18 elicited canonical PTI defense responses in plants, as well as inducing resistance to PPNs and to microbial pathogens (Manosalva et al. 2015). Notably, the yet to be identified ascaroside receptor is likely conserved among distinct plant species, as the elicitation of defense responses was conserved in dicotyledonous and monocotyledonous plants such as Arabidopsis, tomato, potato, and barley (Manosalva et al. 2015).

Different sources for NAMPs have been used to study plant early responses. Crude tissue extracts of infective-stage juveniles was shown to induce defense marker genes in Arabidopsis roots (Teixeira et al. 2016). In addition, treatment with this extract induced root enlargement similar to symptoms cause by nematode infection indicating that both defense and morphological alteration cues are present in the extract (Teixeira et al. 2016). Another source of NAMPs used to date is NemaWater, water in which infectivestage juveniles have been incubated. Treating roots with NemaWater triggered a ROS burst and defense gene induction in roots, indicating activation of defense responses suggesting the presence of an immune elicitor(s) (Mendy et al. 2017). Similar to microbial pathogens, it is expected that nematodes also have a number of different NAMPs. Currently, it is unclear how many different elicitors are present in the nematode extract or in the NemaWater. However, the elicitor(s) in the NemaWater is heat-labile and likely proteinaceous in nature as heat or proteinase $\mathrm{K}$ treatment of NemaWater led to significant attenuation of the observed defense responses (Mendy et al. 2017).

\section{PERCEPTION OF NEMATODES}

Considering penetration of nematodes and migration inside plant tissues, cellular damage could be caused by their actions. In addition, PPNs secrete cell wall degrading enzymes that may release cellular components that act as self danger molecules known as damage-associated molecular patterns (DAMPs) (Ali et al.
2017). Similar to recognition of MAMPs or NAMPs, DAMPs also trigger defense responses (Mott et al. 2014). DAMPs were originally described as a result of cell wall rupture, releasing fragments that are recognized by adjacent cells, such as oligogalacturonides (OGs), produced by the activity of pathogen-encoded enzymes. In addition, ATP, known to activate immunity in animals was also characterized as a plant DAMP, and its plant receptor, DOES NOT RESPOND TO NUCELOTIDES 1 (DORN1), was recently identified (Cao et al. 2014; Choi et al. 2014). A second type of DAMP is transcriptionally regulated where damage leads to transcription of long protein precursors (PROPEPs), that are cleaved and generate small peptides Atpep1-8, which are recognized by the PEP receptors (PEPRs) 1 and 2 (Bartels and Boller 2015; Huffaker et al. 2006). PROPEPs are also induced by pathogen infections and herbivore saliva. These plant endogenous signals seem widely conserved as homologs of PROPEPs have been identified in numerous crop species (Huffaker at al. 2006).

Infecting Arabidopsis single or double mutants of these three DAMP receptors, dorn1, pepr1 and pepr2 or pepr1 pepr2, with $M$. incognita did not result in a difference in phenotypes compared with wild-type suggesting that DAMP recognition alone might not play a significant role in defense against $M$. incognita (Teixeira et al. 2016). Interestingly, treatment of soybean seeds with three soybean elicitor peptides (GmPep1, GmPep2, and GmPep3), and activation of defense responses, resulted in reduced reproduction of both $H$. glycines and $M$. incognita (Lee et al. 2018). Taken together this information indicates that although DAMP recognition through these receptors is not involved in RKN perception, activation of defense responses contributes to RKN resistance. Contrary to RKNs that penetrate roots intercellularly and cause minimum cell damage, CNs penetrate root tissues intracellularly, cause extensive visible damage during infection and migration and therefore are expected to generate DAMPs. Whether these DAMP receptors participate in CN perception remains unknown. Nevertheless, identification of the GmPeps in soybean suggests such elicitor peptides could be present also in other crop species, and used to induce defense against PPNs, promising a novel approach to control nematodes in a wide variety of crops.

\section{RESISTANCE GENES AND BREEDING FOR RESISTANCE}

Identification and incorporation of diseases resistance $(R)$ genes have been historically important tools to manage nematode infections. The challenge has always been the labor intensive and time-consuming nature of the nematode pathogenicity assays during the breeding process. As with other pathosystems, genetics of resistance to nematodes varies greatly. However, all single gene resistance loci against nematodes identified to date are for the sedentary endoparasites, RKNs, and $\mathrm{CNs}$, while resistance/ tolerance to migratory endoparasites are mostly determined by QTLs and none have been cloned to date (Jones et al. 2016).

A large number of resistance sources to RKNs have been identified in various plant taxa (Williamson and Roberts 2009). In addition, multiple resistances with distinct specificity against a particular species of RKN have been identified for crops, such as tomato, pepper, cotton, or grain legumes. However, the majority of these resistances have not been introgressed into elite crop cultivars. Although the focus of resistance to RKN has been on single dominant resistance types, the inheritance of resistance to this group of nematodes varies, ranging from recessive inheritance to major and minor QTL combinations. With the advent of molecular marker analysis and marker-assisted breeding, it is expected that the introgression of all types of resistances will accelerate.

Similar to resistance genes against microbial pathogens, nematode resistance genes also show clustered genomic arrangement. One of the better-known RKN resistance gene clusters is 
located on chromosome 6 of tomato where the well-known $\mathrm{Mi}-1$ resistance gene resides (Seah et al. 2007). Within this cluster, in addition to RKN resistance genes, reside resistance genes to the fungal pathogens Oidium neolycopersici (OI-1) and Cladosporium fulvum (Cf2/Cf5), the bacterial pathogen Ralstonia solanacearum ( $\mathrm{Bw}-5)$, as well as the alfalfa mosaic virus (Am) and tomato yellow leaf curl virus (TY1/TY3) (Dixon et al. 1998, 1996; Parrella et al. 2004; Seifi et al. 2011; Thoquet et al. 1996; Verlaan et al. 2013). These resistances are encoded by proteins with varied predicted structures, making it one of the most diverse resistance hot spots in crops.

\section{RKN RESISTANCE GENES AND GENE STRUCTURE}

Among the first group of resistance genes cloned in the mid to late 1990s was the Mi-1 gene (Milligan et al. 1998; Vos et al. 1998). Mi-1, initially identified in the wild tomato relative, Solanum peruvianum, confers resistance to three RKN species, $M$. incognita, $M$. javanica, and $M$. arenaria. To date, with over 20 years since cloning $M i-1$, it is remarkable that only one other RKN resistance gene, $M a$, has been cloned and its function demonstrated in the plant species from which it was cloned. The $M a$ resistance locus was isolated from the Myrobalan plum Prunus cerasifera (Claverie et al. 2011). Meanwhile, a large number of resistance genes to microbial pathogens have been cloned, their function complemented in the susceptible plant species, and a wealth of information on their modes of pathogen recognition and signaling (Kourelis and van der Hoorn 2018). This dearth of RKN cloned resistance genes, and resistance genes against nematodes in general, suggest difficulty in identifying the $R$-genes, functional analysis by complementation in the respective plant species, or lack of interest in sustainable funding for such work. Indeed, an additional RKN gene PsoRPM2 was recently cloned from the wild Myrobalan plum Prunus sogdiana, but complementation was performed in tobacco pointing to technical difficulties in transforming certain plant species (Zhu et al. 2017).

Earlier, an alternate approach to cloning was used to identify the nature of an RKN resistance gene, $M i-9$. Mi-9 was identified in the wild relative of tomato, Solanum arcanum accession LA2157, mediates heat-stable resistance to the same spectrum of RKN as $M i$-1. Unlike $M i$-1-mediated resistance that breaks down at soil temperatures above $28^{\circ} \mathrm{C}, M i-9$-mediated resistance is active at high temperatures (Ammiraju et al. 2003). Mi-9 is localized to the short arm of chromosome 6 of tomato, in a similar location as the $\mathrm{Mi}$ locus. Since the short arm of chromosome 6 contains several members of the $M i-1$ gene family, it was speculated that $M i-9$ could be a homolog of $M i-1$. RKN resistance at high temperature in S. arcanum LA2157 was attenuated when a 300-bp cDNA, spanning the carboxyl end of Mi-1, was used in tobacco rattle virus (TRV)based virus-induced gene silencing (VIGS), indicating that $\mathrm{Mi}$-9mediated resistance in accession LA2157 is indeed encoded by a $M i-1$ homolog (Jablonska et al. 2007). Since $M i-9$ was identified by gene silencing and not by cloning and complementation, the exact sequence of $M i-9$ remains unknown.

\section{STRUCTURE OF Mi AND Ma LOCI AND ENCODED PROTEINS}

To date, only two $R$-genes against RKN have been cloned, $M i-1$ and $M a$. Both $R$-genes encode nucleotide-binding leucine-rich repeat (NLR) proteins with no subcellular localization signals and are presumed to be cytoplasmically localized (Claverie et al. 2011; Milligan et al. 1998). Both $M i$ and $M a$ loci also have similar structure encompassing both genes and pseudogenes. The Mi locus, located on the short arm, near the centromere, of chromosome 6 of tomato spans about a $30-\mathrm{kb}$ region, and contains two complete NLR genes, $M i-1.2$ and $M i-1.1$, and a pseudogene, $M i-1.3$. Tomato complementation experiments, with the respective native promoters, showed that $M i-1.2$, also referred to as $M i-1$, and not
$M i-1.1$ confers resistance to RKN. The $M a$ resistance locus contains three NLR encoding sequences, two of which are pseudogenes or truncated genes and only one encodes a full-length gene sequence, the $M a$ gene. $M a$, with its native promoter was used in complementation experiments by Agrobacterium rhizogenesmediated transformation of susceptible Prunus as hairy root transformation as well as composite microplants. Both approaches showed that the presence of this single NLR conferred resistance to RKN confirming that it is the Ma R-gene (Claverie et al. 2011).

While Mi-1 and Ma are both NLRs, these R proteins feature stark differences. The $\mathrm{N}$-terminus of Mi-1 has a coiled-coil (CC) domain while the $\mathrm{N}$-terminus of Ma displays a Toll interleukin1 receptor (TIR) domain (Milligan et al. 1998; Vos et al. 1998). In addition, while Mi-1 has a long amino terminus, commonly displayed among NLRs from solanaceous plants, the Ma protein has an unusually long carboxy-terminus. This long carboxy-terminal region contains a WRKY-like domain (Claverie et al. 2011; Van Ghelder and Esmenjaud 2016). Since WRKYs are transcription factors known for their role in regulating immune responses, the presence of WRKY-like sequences suggests the ability of Ma to integrate effector recognition and defense signaling networks. Alternatively, the WRKY-like domain may serve as an effector target and a decoy bait as has been shown for other NLR-WRKY R proteins (Baggs et al. 2017).

In addition to $M i-1$, a few $\mathrm{CN} R$-genes have been cloned from solanaceous plant species, namely Gpa2 and Grol-4 from potato and Hero from tomato. Gpa2 and Hero encode CC-NLRs while Grol-4 encodes a TIR-NLR (Kaloshian et al. 2011). A recent review describes the recently cloned soybean $\mathrm{CN} R$-loci, $r$ hgl and $R h g 4$, from soybeans that encode surprising and novel types of resistance proteins (Mitchum 2016). The vast structural and composition differences among the nematode resistance loci cloned to date highlights the diversity of $R$-genes and possible mechanisms of resistance that includes both activation of immune responses and alterations in plant metabolism. This diversity also highlights one of the challenges to identify and clone PPN $R$-genes.

\section{Mi-1 AND Ma: RESISTANCE SPECTRUM AND MECHANISM OF RESISTANCE}

Most NLRs confer resistance to a specific race or strain of pathogen or nematode. In contrast, $M i-1$ confers resistance to two distinct taxa of pests, nematodes and insects. Besides conferring resistance to three species of RKNs, $M i-1$ confers resistance to three species of Hempiteran insects, potato aphids (Macrosiphum euphorbiae), whiteflies (Bemisia tabaci), and psyllids (Bactericerca cockerelli) (Kaloshian et al. 2011). How a single NLR recognizes all these different groups of pests remains a mystery. The broad-spectrum resistance conferred by $\mathrm{Mi}-1$ suggests that either these organisms share a common conserved motif, suggesting direct recognition, or that they leave similar footprints or have effectors converging on the same immunity hub guarded by Mi-1. To date, no insect effectors that Mi-1 recognizes have been identified. Two genes that are uniquely expressed in $M i-1$ avirulent $\mathrm{RKN}$ populations, and not in virulent near-isogenic populations, have been isolated (Gleason et al. 2008; Semblat et al. 2001). However, it is not clear whether either one of these genes is the effector that Mi-1 recognizes (discussed in the next section).

The mechanism of resistance to $\mathrm{RKN}$ in herbaceous plants varies from hypersensitive response (HR) and no initiation of feeding site to late necrosis and imperfect giant cell formation. $M i$ - 1 -mediated resistance to $\mathrm{RKN}$ in tomato roots is manifested by $\mathrm{HR}$, accumulation of $\mathrm{H}_{2} \mathrm{O}_{2}$ and no initiation of a visible feeding site indicating that nematodes either die from starvation or exit resistant roots (Kaloshian et al. 2011). Unlike RKNs, aphids are able to initiate feeding on resistant tomato leaves and no HR is detected (Martinez de Ilarduya et al. 2003). However, aphids are unable to 
sustain feeding and die, likely from starvation. Although $R$-genemediated resistance has been uncoupled from $H R$, it is not clear whether this difference in $\mathrm{Mi}$-1-mediated RKN and aphid resistance is due to the different plant tissues involved, leaves versus roots, or possibly the differential level of $M i-1$ expression in these distinct tissue types.

The resistance mediated by the $M a$ gene also involves HR. Infective-stage juveniles are able to penetrate both resistant and susceptible plum root tips, but in resistant roots, infective-stage juveniles are unable to move out of the apical meristem region, do not initiate a feeding site or develop (Saucet et al. 2016). In spite of a similar resistance mechanism against RKN, the $M a$ and $M i-1 R$ genes differ regarding their spectrum of resistance. While Mi-1 confers resistance to diverse organisms, the $M a$ gene displays broad-spectrum resistance to RKN species. $M a$ confers resistance against over $30 \mathrm{RKN}$ species and populations but it is not clear what type of nematode effector or trigger it recognizes (Saucet et al. 2016). This type of resistance is similar to the rice resistance gene $\mathrm{Xa21}$ with broad-spectrum resistance to various strains of Xanthomonas oryzae pv. oryzae (Song et al. 1995). Considering that Xa21 immune activity is triggered by a 21-amino acid RaxX peptide (RaxX21-sY) (Pruitt et al. 2015), it is likely that Ma also recognizes a common peptide or NAMP shared by diverse RKN species. Xa21 and other MAMP recognition receptors are cell surface localized and mostly directly interact with their cognate MAMPs. Considering that $M a$ encodes an intracellular receptor, it is unclear how it comes into contact with the NAMP and whether it directly interacts with the ligand.

\section{RESISTANCE BREAKING RKN AND RKN EFFECTORS}

In a number of resistant plant-RKN interactions, differences in the ability of nematodes to reproduce have been reported. Numerous reports have indicated the presence of $M$. incognita and $M$. javanica populations that are able to infect and reproduce on tomato plants carrying $M i-1$. Most of these RKN virulent populations are reported from fields that have been repeatedly planted with resistant tomato suggesting that virulence has developed as a consequence of genetic pressure. In addition, sometimes a fitness cost, such as the ability to reproduce at high levels on the susceptible plant or on other crops, has been associated with the appearance of virulence (Williamson and Roberts 2009). However, virulence on $\mathrm{Mi}$-1-containing tomatoes has also been reported in fields with no history of resistant tomato cropping indicating an inherent ability to adapt quickly to resistant cultivars (Kaloshian et al. 1996; Netscher 1976). How do these latter virulent RKN populations overcome $M i-1$-mediated resistance is puzzling considering their parthenogenetic mode of reproduction and our understanding of the evolution of $R$-genes, and may suggest either transcriptional plasticity of effectors or an active dynamic genome.

To identify the genetics of virulence and to identify the RKN effector that $M i-1$ recognizes, nearly-isogenic RKN strains that differ in virulence on Mi-1 carrying tomato, were used in transcriptome analyses (Gleason et al. 2008; Semblat et al. 2001). In these reports, losses of the expression of single, but distinct genes, were identified in the virulent isolates compared with their avirulent counterparts. One of these genes named map-1.2, encodes an expansin-like protein secreted by the nematode and is likely involved in nematode penetration. MAP1.2 has 58 and 13 amino acid repeat units and belongs to a small gene family with variation in the number of these repeat units. Interestingly, members of the MAP1 family are unique to Meloidogyne species with a mitotic parthenogenetic mode of reproduction and are not present in other species of nematodes or in RKNs with other modes of reproduction (Tomalova et al. 2012). The loss of map-1.2 was detected in the genome of additional $M i-1$ virulent RKNs, indicating genetic adaptation to new conditions in these parthenogenetic organisms and further substantiating a link between virulence and the absence of this gene (Castagnone-Sereno et al. 2009). However, besides association with avirulence, the role of map-1 in $\mathrm{Mi}$-1-mediated resistance remains unclear.

The second gene identified using $M i-1$ virulent and avirulent near-isogenic RKN strains and differential transcriptome analysis is $C g-1$ (Gleason et al. 2008). Similar to mapl, $C g-1$ is also expressed in the $M i-1$ avirulent strain and missing from the virulent strain. Consistent with a role for $C g-1$ in $\mathrm{Mi}-1$-mediated resistance, silencing $C g-1$ in the avirulent RKN strain, by soaking in doublestranded RNA, resulted in gain of virulence function. It is not clear what $C g-1$ encodes as no annotation for this gene exists and it is not known whether $\mathrm{Cg}-\mathrm{l}$ expression is also missing in additional $\mathrm{Mi}-1.2$ virulent RKN populations. Consequently, the role of $\mathrm{Cg}-\mathrm{I}$ in $\mathrm{Mi}-\mathrm{I}$ mediated resistance remains vague and the quest for the RKN effector that $\mathrm{Mi}-1$ recognizes continues.

Recent research suggests that gene copy number variation could be responsible for the genetic variation and adaptation of virulent RKN isolates to $M i-1$ carrying tomato plants. Using two nearly isogenic $M i-1$ virulent and avirulent RKN pairs, 33 genes were identified that showed decreases in copy number in the two virulent pairs compared with the avirulent (Castagnone-Serrano et al. 2019). High level of variation in gene copy number has been observed in various asexual organisms and thought to be one of the genomic mechanisms used by these organisms to cope with selective pressure and adaptation to their environments (Duvaux et al. 2015; Minning et al. 2011; Spring et al. 2013). Interestingly, the ontology of these RKN genes indicate enrichment in functions involved in parasitism and further supports the notion that gene copy loss is a virulence mechanism in asexual RKNs (Castagnone-Serrano et al. 2019). However, whether these RKN gene products are secreted into the plant and how they interact with $\mathrm{Mi}-1$ and evade $\mathrm{Mi}-1$ mediated resistance remains unclear.

Characterization of secreted nematode proteins and identification of effectors is of great interest to the PPN scientific community (Mantelin et al. 2017). At this time, several projects across different continents are studying nematode effector biology in the hope of identifying the ways PPNs manipulate their hosts for their advantage. Current information indicates that PPN secretions are not only essential for host penetration and feeding site formation, but also do indeed interfere with plant immune responses (Mantelin et al. 2015). Among these is the RKN effector calreticulin, Mi-CRT, that has been shown to suppress PTI responses induced by the bacterial MAMP elf18 (Jaouannet et al. 2013). The success of RKNs as parasites, and the large number of secreted proteins identified from them, suggests the presence of additional effectors that suppress plant defenses (Bellafiore et al. 2008).

\section{WHAT MORE WE KNOW ABOUT Mi-1 SIGNALING?}

Structure-function analysis indicates that the Mi-1 LRR domain is involved in effector recognition and upon this recognition, Mi-1 protein undergoes a conformational change that activates immune responses. Activation also involves binding to and hydrolysis of ATP to ADP (Tameling et al. 2002). Additional Mi-1 signaling components, common in other NLR signaling cascades, have been identified including Hsp90 and Sgt1 (Fig. 2). Downstream defense signals also include members of mitogen-activated protein (MAP) kinase cascade and the transcription factors WRKY70a/b and WRKY72 (Kaloshian et al. 2011). Rme1, a gene identified through mutagenesis of resistant tomato, is also required for $M i$ - 1 -mediated resistance and thought to function early in the signaling cascade, likely as a common target for RKN and insect pests guarded by Mi-1 (Martinez de Ilarduya et al. 2001). However, Rmel has not yet been cloned and its nature and the exact role in $\mathrm{Mi}-\mathrm{l}$-mediated resistance remains unknown.

Recent information indicates that Mi-1 interacts with the cell surface localized receptor-like kinase, SERK1. Using a VIGS 
screen as a reverse genetic tool, SERK1 was identified to be required for $\mathrm{Mi}$-1-mediated cell death in $N$. benthamiana (Mantelin et al. 2011). Similarly, the requirement of SERK1 for Mi-1 resistance against aphids was shown in tomato using VIGS. Interestingly, silencing SERK1 in tomato did not affect RKN resistance (Mantelin et al. 2011). Since VIGS does not completely eliminate the targeted gene transcripts, it is likely that SERK1 also functions in resistance against RKN and that the residual SERK1 levels in the silenced roots is sufficient for Mi-1 function. In addition to SERK1, a recent discovery indicates that Mi-1 cell death in $N$. benthamiana leaves requires a second NLR, known as NRC4 (NLR required for cell death 4), that is suggested to be a core element of the plant immune signaling network (Wu et al. 2017). Earlier, another NRC, NRC1 was also shown to be required for autoactive $\mathrm{Mi}-1$ cell death in $N$. benthamiana (Gabriels et al. 2007). These discoveries demonstrate the complex nature of the Mi-1 signaling network that connects multiple components spanning the cell surface to the cell nucleus (see more below).

The association of SERK1 and Mi-1 was further demonstrated by colocalization of SERK1 and Mi-1 at the plasma membrane, and coimmunoprecipitation of SERK1 and Mi-1 in a single protein complex in the resistant tomato microsomal fractions (Peng et al. 2016). More interestingly, SERK1 and Mi-1 were shown to directly interact only upon ligand recognition. The ligand recognition may bring a conformational change in SERK1 and/or Mi-1 consistent with the need for a conformational change(s) to activate $M i$ - 1 -mediated immunity (Takken et al. 2006). Furthermore, besides its presence in the microsomal and cytoplasmic compartments, Mi-1 was also detected in the nucleus indicating its presence in different subcellular regions (Peng et al. 2016). The presence of Mi-1 in microsomal fractions as well as the cytoplasm and the nucleus, may highlight the importance of its presence in multiple subcellular compartments for effective activation of defenses. Whether such compartmentalization is necessary for Mi-1 function and the function of RKN NLR R proteins remains to be seen.

\section{DEFENSE RESPONSES AGAINST RKNS}

Plants depend on hormonal networks to fine tune responses to biotic and abiotic stressors and to regulate growth and defense tradeoffs. The major hormones that regulate plant defense responses are salicylic acid (SA), jasmonic acid (JA), and ethylene (ET). For a long time, SA has been associated with defense against biotrophic pathogens while JA/ET contributing to defense against necrotrophic pathogens and herbivore pests. A synergistic interaction between JA and ET has also been established as has the existence of an antagonistic relationship between SA and JA/ ET responses. However, recent information indicates that all three hormone signaling pathways, SA, JA, and ET, interact at a synergistic level with one hormone making a larger contribution than the others based on the specific stressor (Tsuda et al. 2009). Although defense against PPN involves all three major hormones, existing information reports contradictory outcomes for both $\mathrm{RKN}$ and $\mathrm{CN}$ infections. A detailed review on the role of phytohormones in plant-PPN interactions was published recently elsewhere (Gheysen and Mitchum 2019). The emerging consensus indicates that ET inhibits RKN infection and promotes $\mathrm{CN}$ infection while SA contributes to defense against both RKN and $\mathrm{CN}$. The picture with the JA phytohormone seems more complex particularly against RKN. While a clear positive role for JA in defense against $\mathrm{CN}$ has emerged, the role of JA in RKN defense is not well defined. What is clear is the lack of consensus on the role of JA in RKN defense and that different branches of the oxylipin pathway that includes JA biosynthesis contribute differently to RKN defense.

\section{CONCLUDING REMARKS}

The progress toward cloning and incorporating RKN resistance genes into cultivated crops remains surprisingly slow. Although the reasons for this slow progress are not well articulated, it is clear that lack of sustained funding and consequently low number of researchers in this field are major contributors for this disappointing progress. There is much to learn about PPNs and interactions with their hosts. Outstanding important questions remain as to the cause of virulence, the nature of RKN effectors recognized by R-proteins and the immediate downstream signals, the diversity of RKN R-proteins and whether atypical R-proteins, like those against CNs, also exist for RKNs. The lack of genetic variation and asexual reproduction of the most agronomically important RKN species, necessitates systematic analysis of genomic, transcriptomic and proteomic data sets to unravel these questions. Potential use of alternatives to $R$-genes in controlling PPNs are emerging, but are far from being implemented for their control. For the foreseeable future, reliance on chemicals to control PPNs, particularly RKNs, will continue.

\section{ACKNOWLEDGMENTS}

We thank J. He for help with references. We apologies to those colleagues whose works were not referenced due to space limitation.

\section{LITERATURE CITED}

Abad, P., Gouzy, J., Aury, J. M., Castagnone-Sereno, P., Danchin, E. G., Deleury, E., Perfus-Barbeoch, L., Anthouard, V., Artiguenave, F., Blok, V. C., Caillaud, M. C., Coutinho, P. M., Dasilva, C., De Luca, F., Deau, F., Esquibet, M., Flutre, T., Goldstone, J. V., Hamamouch, N., Hewezi, T., Jaillon, O., Jubin, C., Leonetti, P., Magliano, M., Maier, T. R., Markov, G. V., McVeigh, P., Pesole, G., Poulain, J., Robinson-Rechavi, M., Sallet, E., Segurens, B., Steinbach, D., Tytgat, T., Ugarte, E., van Ghelder, C., Veronico, P., Baum, T. J., Blaxter, M., Bleve-Zacheo, T., Davis, E. L., Ewbank, J. J., Favery, B., Grenier, E., Henrissat, B., Jones, J. T., Laudet, V., Maule, A. G., Quesneville, H., Rosso, M. N., Schiex, T., Smant, G., Weissenbach, J., and Wincker, P. 2008. Genome sequence of the metazoan plant-parasitic nematode Meloidogyne incognita. Nat. Biotechnol. 26:909-915.

Ali, M. A., Azeem, F., Li, H. J., and Bohlmann, H. 2017. Smart parasitic nematodes use multifaceted strategies to parasitize plants. Front. Plant Sci. 8:1699.

Ammiraju, J. S. S., Veremis, J. C., Huang, X., Roberts, P. A., and Kaloshian, I. 2003. The heat-stable root-knot nematode resistance gene $\mathrm{Mi}-9$ from Lycopersicon peruvianum is localized on the short arm of chromosome 6 . Theor. Appl. Genet. 106:478-484

Baggs, E., Dagdas, G., and Krasileva, K. V. 2017. NLR diversity, helper and integrated domains: Making sense of the NLR IDentity. Curr. Opin. Plant Biol. 38:59-67.

Bartels, S., and Boller, T. 2015. Quo vadis, Pep? Plant elicitor peptides at the crossroads of immunity, stress, and development. J. Exp. Bot. 66:5183-5193.

Bellafiore, S., Shen, Z. X., Rosso, M. N., Abad, P., Shih, P., and Briggs, S. P. 2008. Direct identification of the Meloidogyne incognita secretome reveals proteins with host cell reprogramming potential. PLoS Pathog 4:e1000192.

Bohm, H., Albert, I., Fan, L., Reinhard, A., and Nurnberger, T. 2014. Immune receptor complexes at the plant cell surface. Curr. Opin. Plant Biol. 20:47-54.

Cao, Y. R., Tanaka, K., Nguyen, C. T., and Stacey, G. 2014. Extracellular ATP is a central signaling molecule in plant stress responses. Curr. Opin. Plant Biol. 20:82-87.

Castagnone-Sereno, P., Mulet, K., Danchin, E. G. J., Koutsovoulos, G. D., Karaulic, M., Da Rocha, M., Bailly-Bechet, M., Pratx, L., Perfus-Barbeoch, L., and Abad, P. 2019. Gene copy number variations as signatures of adaptive evolution in the parthenogenetic, plant-parasitic nematode Meloidogyne incognita. Mol. Ecol. 28:2559-2572.

Castagnone-Sereno, P., Semblat, J. P., and Castagnone, C. 2009. Modular architecture and evolution of the map-1 gene family in the root-knot nematode Meloidogyne incognita. Mol. Genet. Genomics 282:547-554.

Choe, A., von Reuss, S. H., Kogan, D., Gasser, R. B., Platzer, E. G., Schroeder, F. C., and Sternberg, P. W. 2012. Ascaroside signaling is widely conserved among nematodes. Curr. Biol. 22:772-780.

Choi, J., Tanaka, K., Cao, Y., Qi, Y., Qiu, J., Liang, Y., Lee, S. Y., and Stacey, G. 2014. Identification of a plant receptor for extracellular ATP. Science 343:290-294.

Claverie, M., Dirlewanger, E., Bosselut, N., Van Ghelder, C., Voisin, R., Kleinhentz, M., Lafargue, B., Abad, P., Rosso, M. N., Chalhoub, B., and 
Esmenjaud, D. 2011. The Ma gene for complete-spectrum resistance to Meloidogyne species in Prunus is a TNL with a huge repeated c-terminal post-LRR region. Plant Physiol. 156:779-792.

Curtis, R. H. C., Robinson, A. F., and Ronald, N. P. 2009. Hatch and host location. Pages 139-162 in: Root-Knot Nematodes. M. Moens, R. N. Perry, and J. L. Starr, eds. CABI, Wallingford, U.K.

Davies, K. G., and Curtis, R. H. C. 2011. Cuticle surface coat of plant-parasitic nematodes. Annu. Rev. Phytopathol. 49:135-156.

De Veer, M. J., Kemp, J. M., and Meeusen, E. N. T. 2007. The innate host defence against nematode parasites. Parasite Immunol. 29:1-9.

Decraemer, W., and Hunt, D. J. 2006. Structure and classification. Pages 3-32 in: Plant Nematology. R. N. Perry and M. Moens, eds. CABI, Wallingford, U.K./Cambridge, MA.

Dixon, M. S., Hatzixanthis, K., Jones, D. A., Harrison, K., and Jones, J. D. 1998. The tomato $C f-5$ disease resistance gene and six homologs show pronounced allelic variation in leucine-rich repeat copy number. Plant Cell 10:1915-1925.

Dixon, M. S., Jones, D. A., Keddie, J. S., Thomas, C. M., Harrison, K., and Jones, J. D. G. 1996. The tomato $C f$-2 disease resistance locus comprises two functional genes encoding leucine-rich repeat proteins. Cell 84: 451-459.

dos Santos, M. F. A., Furlanetto, C., Almeida, M. R. A., Carneiro, M. D. G., Mota, F. C., Gomes, A. C. M. M., Silveira, N. O. R., Silva, J. G. P., Castagnone-Sereno, P., Tigano, M. S., and Carneiro, R. M. D. G. 2012. Biometrical, biological, biochemical and molecular characteristics of Meloidogyne incognita isolates and related species. Eur. J. Plant Pathol. 134:671-684.

Duvaux, L., Geissmann, Q., Gharbi, K., Zou, J. J., Ferrai, J., Smadja, C. M., and Butlin, R. K. 2015. Dynamics of copy number variation in host races of the pea aphid. Mol. Biol. Evol. 32:63-80.

Favery, B., Quentin, M., Jaubert-Possamai, S., and Abad, P. 2016. Gallforming root-knot nematodes hijack key plant cellular functions to induce multinucleate and hypertrophied feeding cells. J. Insect Physiol. 84:60-69.

Fosu-Nyarko, J., and Jones, M. G. K. 2016. Advances in understanding the molecular mechanisms of root lesion nematode host interactions. Annu. Rev. Phytopathol. 54:253-278.

Fudali, S. L., Wang, C. L., and Williamson, V. M. 2013. Ethylene signaling pathway modulates attractiveness of host roots to the root-knot nematode Meloidogyne hapla. Mol. Plant-Microbe Interact. 26:75-86.

Gabriels, S. H. E. J., Vossen, J. H., Ekengren, S. K., van Ooijen, G., Abd-El-Haliem, A. M., van den Berg, G. C. M., Rainey, D. Y., Martin, G. B., Takken, F. L. W., de Wit, P. J. G. M., and Joosten, M. H. A. J. 2007. An NB-LRR protein required for HR signalling mediated by both extra- and intracellular resistance proteins. Plant J. 50:14-28.

Gheysen, G., and Mitchum, M. G. 2019. Phytoparasitic nematode control of plant hormone pathways. Plant Physiol. 179:1212-1226.

Gleason, C. A., Liu, Q. L., and Williamson, V. M. 2008. Silencing a candidate nematode effector gene corresponding to the tomato resistance gene Mi-1 leads to acquisition of virulence. Mol. Plant-Microbe Interact. 21:576-585.

Hartman, K. M., and Sasser, J. N. 1985. Identification of Meloidogyne species on the basis of differential host test and perineal-pattern morphology. Pages 69-77 in: Advanced Treatise on Meloidogyne. K. R. Barker, C. C. Carter, and J. N. Sasser, eds. North Carolina University, Raleigh.

Holbein, J., Grundler, F. M., and Siddique, S. 2016. Plant basal resistance to nematodes: An update. J. Exp. Bot. 67:2049-2061.

Hu, Y., You, J., Li, C., Williamson, V. M., and Wang, C. 2016. Ethylene response pathway modulates attractiveness of plant roots to Heterodera glycines. J. Nematol. 48:332.

Huffaker, A., Pearce, G., and Ryan, C. A. 2006. An endogenous peptide signal in Arabidopsis activates components of the innate immune response. Proc. Natl. Acad. Sci. USA 103:10098-10103.

Jablonska, B., Ammiraju, J. S. S., Bhattarai, K. K., Mantelin, S., de Ilarduya, O. M., Roberts, P. A., and Kaloshian, I. 2007. The Mi-9 gene from Solanum arcanum conferring heat-stable resistance to root-knot nematodes is a homolog of Mi-1. Plant Physiol. 143:1044-1054.

Jaouannet, M., Magliano, M., Arguel, M. J., Gourgues, M., Evangelisti, E., Abad, P., and Rosso, M. N. 2013. The root-knot nematode calreticulin MiCRT is a key effector in plant defense suppression. Mol. Plant-Microbe Interact. 26:97-105.

Jones, G. K., Iqbal, S., and Fosu-Nyarko, J. 2016. Belowground defence strategies against migratory nematodes. Pages 253-278 in: Belowground Defence Strategies in Plants. C. Vos and K. Kazan, eds. Springer International Publishing, Cham.

Jones, J. T., Haegeman, A., Danchin, E. G. J., Gaur, H. S., Helder, J., Jones, M. G. K., Kikuchi, T., Manzanilla-Lopez, R., Palomares-Rius, J. E., Wesemael, W. M. L., and Perry, R. N. 2013. Top 10 plant-parasitic nematodes in molecular plant pathology. Mol. Plant Pathol. 14:946-961.
Juvale, P. S., and Baum, T. J. 2018. "Cyst-ained" research into Heterodera parasitism. PLoS Pathog. 14:e1006791.

Kaloshian, I., Desmond, O., and Atamian, H. S. 2011. Disease resistance genes and defense responses during incompatible interactions. Pages 309-324 in: Genomics and Molecular Genetics of Plant-Nematode Interactions. J. Jones, G. Gheysen, and C. Fenoll, eds. Springer. Dordrecht, Heidelberg, London, New York.

Kaloshian, I., Williamson, V. M., Miyao, G., Lawn, D. A., and Westerdahl, B. B. 1996. "Resistance breaking" nematodes identified in California tomatoes. Calif. Agric. 50:18-19.

Kammerhofer, N., Radakovic, Z., Regis, J. M., Dobrev, P., Vankova, R., Grundler, F. M., Siddique, S., Hofmann, J., and Wieczorek, K. 2015. Role of stress-related hormones in plant defence during early infection of the cyst nematode Heterodera schachtii in Arabidopsis. New Phytol. 207:778-789.

Kourelis, J., and van der Hoorn, R. A. L. 2018. Defended to the nines: 25 years of resistance gene cloning identifies nine mechanisms for $\mathrm{R}$ protein function. Plant Cell 30:285-299.

Koutsovoulos, G. D., Marques, E., Arguel, M.-J., Duret, L., Machado, A. C. Z., Carneiro, R. M. D. G., Kozlowski, D. K., Bailly-Bechet, M., Castagnone-Sereno, P., Albuquerque, E. V. S., and Danchin, E. G. J. 2019. Population genomics supports clonal reproduction and multiple gains and losses of parasitic abilities in the most devastating nematode plant pest. bioRxiv 362129.

Lee, M. W., Huffaker, A., Crippen, D., Robbins, R. T., and Goggin, F. L. 2018. Plant elicitor peptides promote plant defences against nematodes in soybean. Mol. Plant Pathol. 19:858-869.

Manosalva, P., Manohar, M., von Reuss, S. H., Chen, S. Y., Koch, A., Kaplan, F., Choe, A., Micikas, R. J., Wang, X. H., Kogel, K. H., Sternberg, P. W., Williamson, V. M., Schroeder, F. C., and Klessig, D. F. 2015. Conserved nematode signalling molecules elicit plant defenses and pathogen resistance. Nat. Commun. 6:7795.

Mantelin, S., Peng, H. C., Li, B. B., Atamian, H. S., Takken, F. L. W., and Kaloshian, I. 2011. The receptor-like kinase SISERK1 is required for Mi-1mediated resistance to potato aphids in tomato. Plant J. 67:459-471.

Mantelin, S., Thorpe, P., and Jones, J. T. 2015. Suppression of plant defences by plant-parasitic nematodes. Pages 325-337 in: Plant Nematode Interactions: A View on Compatible Interrelationships. C. Escobar and C. Fenoll, eds. Academic Press, Oxford.

Mantelin, S., Thorpe, P., and Jones, J. T. 2017. Translational biology of nematode effectors. Or, to put it another way, functional analysis of effectors-What's the point? Nematology 19:251-261.

Martinez de Ilarduya, O., Moore, A. E., and Kaloshian, I. 2001. The tomato Rmel locus is required for $\mathrm{Mi}-1$-mediated resistance to root-knot nematodes and the potato aphid. Plant J. 27:417-425.

Martinez de Ilarduya, O., Xie, Q. G., and Kaloshian, I. 2003. Aphid-induced defense responses in $\mathrm{Mi}-1$-mediated compatible and incompatible tomato interactions. Mol. Plant-Microbe Interact. 16:699-708.

Matsushima, N., and Miyashita, H. 2012. Leucine-rich repeat (LRR) domains containing intervening motifs in plants. Biomolecules 2:288-311.

Mendy, B., Wang'ombe, M. W., Radakovic, Z. S., Holbein, J., Ilyas, M., Chopra, D., Holton, N., Zipfel, C., Grundler, F. M. W., and Siddique, S. 2017. Arabidopsis leucine-rich repeat receptor-like kinase NILR1 is required for induction of innate immunity to parasitic nematodes. PLoS Pathog 13:e1006284.

Milligan, S. B., Bodeau, J., Yaghoobi, J., Kaloshian, I., Zabel, P., and Williamson, V. M. 1998. The root-knot nematode resistance gene $M i$ from tomato is a member of the leucine zipper, nucleotide binding, leucine-rich repeat family of plant genes. Plant Cell 10:1307-1319.

Minning, T. A., Weatherly, D. B., Flibotte, S., and Tarleton, R. L. 2011. Widespread, focal copy number variations (CNV) and whole chromosome aneuploidies in Trypanosoma cruzi strains revealed by array comparative genomic hybridization. BMC Genomics 12:139.

Mitchum, M. G. 2016. Soybean resistance to the soybean cyst nematode Heterodera glycines: An update. Phytopathology 106:1444-1450.

Moens, M., Perry, R. N., and Starr, J. L. 2009. Meloidogyne species-A diverse group of novel and important plant parasites. Pages 1-17 in: RootKnot Nematodes. M. Moens, R. N. Perry, and J. L. Starr, eds. CABI, Wallingford, U.K.

Mott, G. A., Middleton, M. A., Desveaux, D., and Guttman, D. S. 2014. Peptides and small molecules of the plant-pathogen apoplastic arena. Front. Plant Sci. 5:677.

Netscher, C. 1976. Observations and preliminary studies on the occurrence of resistance breaking biotypes of Meloidogyne spp. on tomato.Cah. ORSTOM ser. Biol. XI:173-178.

Parrella, G., Moretti, A., Gognalons, P., Lesage, M. L., Marchoux, G., Gebre-Selassie, K., and Caranta, C. 2004. The Am gene controlling resistance to Alfalfa mosaic virus in tomato is located in the cluster of dominant resistance genes on chromosome 6. Phytopathology 94:345-350. 
Patel, N., Kreider, T., Urban, J. F., and Gause, W. C. 2009. Characterisation of effector mechanisms at the host:parasite interface during the immune response to tissue-dwelling intestinal nematode parasites. Int. J. Parasitol. 39: 13-21.

Peng, H. C., and Kaloshian, I. 2014. The tomato leucine-rich repeat receptorlike kinases SISERK3A and SISERK3B have overlapping functions in bacterial and nematode innate immunity. PLoS One 9:e93302.

Peng, H. C., Mantelin, S., Hicks, G. R., Takken, F. L. W., and Kaloshian, I. 2016. The conformation of a plasma membrane-localized somatic embryogenesis receptor kinase complex is altered by a potato aphid-derived effector. Plant Physiol. 171:2211-2222.

Pruitt, R. N., Schwessinger, B., Joe, A., Thomas, N., Liu, F., Albert, M., Robinson, M. R., Chan, L. J. G., Luu, D. D., Chen, H., Bahar, O., Daudi, A., De Vleesschauwer, D., Caddell, D., Zhang, W. G., Zhao, X. X., Li, X., Heazlewood, J. L., Ruan, D., Majumder, D., Chern, M., Kalbacher, H., Midha, S., Patil, P. B., Sonti, R. V., Petzold, C. J., Liu, C. C., Brodbelt, J. S., Felix, G., and Ronald, P. C. 2015. The rice immune receptor XA21 recognizes a tyrosine-sulfated protein from a Gram-negative bacterium. Sci. Adv. 1:E1500245.

Saucet, S. B., Van Ghelder, C., Abad, P., Duval, H., and Esmenjaud, D. 2016. Resistance to root-knot nematodes Meloidogyne spp. in woody plants. New Phytol. 211:41-56.

Schmid-Hempel, P. 2008. Parasite immune evasion: A momentous molecular war. Trends Ecol. Evol. 23:318-326.

Seah, S., Telleen, A. C., and Williamson, V. M. 2007. Introgressed and endogenous $\mathrm{Mi}-1$ gene clusters in tomato differ by complex rearrangements in flanking sequences and show sequence exchange and diversifying selection among homologues. Theor. Appl. Genet. 114:1289-1302.

Seifi, A., Kaloshian, I., Vossen, J., Che, D. D., Bhattarai, K. K., Fan, J. M., Naher, Z., Goverse, A., Tjallingii, W. F., Lindhout, P., Visser, R. G. F., and Bai, Y. L. 2011. Linked, if not the same, $M i-1$ homologues confer resistance to tomato powdery mildew and root-knot nematodes. Mol. Plant-Microbe Interact. 24:441-450.

Semblat, J. P., Rosso, M. N., Hussey, R. S., Abad, P., and Castagnone-Sereno, P. 2001. Molecular cloning of a cDNA encoding an amphid-secreted putative avirulence protein from the root-knot nematode Meloidogyne incognita. Mol. Plant-Microbe Interact. 14:72-79.

Song, W. Y., Wang, G. L., Chen, L. L., Kim, H. S., Pi, L. Y., Holsten, T., Gardner, J., Wang, B., Zhai, W. X., Zhu, L. H., Fauquet, C., and Ronald, P. 1995. A receptor kinase-like protein encoded by the rice disease resistance gene, Xa21. Science 270:1804-1806.

Spring, K. J., Pham, S., and Zufall, R. A. 2013. Chromosome copy number variation and control in the ciliate Chilodonella uncinata. PLoS One 8: e56413.

Takken, F. L., Albrecht, M., and Tameling, W. I. 2006. Resistance proteins: Molecular switches of plant defence. Curr. Opin. Plant Biol. 9:383-390.

Tameling, W. I., Elzinga, S. D., Darmin, P. S., Vossen, J. H., Takken, F. L., Haring, M. A., and Cornelissen, B. J. 2002. The tomato $R$ gene products I-2 and Mi-1 are functional ATP binding proteins with ATPase activity. Plant Cell 14:2929-2939.

Teixeira, M. A., Wei, L., and Kaloshian, I. 2016. Root-knot nematodes induce pattern-triggered immunity in Arabidopsis thaliana roots. New Phytol. 211: 276-287.

Thoquet, P., Olivier, J., Sperisen, C., Rogowsky, P., Laterrot, H., and Grimsley, N. 1996. Quantitative trait loci determining resistance to bacterial wilt in tomato cultivar Hawaii7996. Mol. Plant-Microbe Interact. 9:826-836.

Tomalova, I., Iachia, C., Mulet, K., and Castagnone-Sereno, P. 2012. The map-1 gene family in root-knot nematodes, Meloidogyne spp.: A set of taxonomically restricted genes specific to clonal species. PLoS One 7: e38656.

Tsuda, K., Sato, M., Stoddard, T., Glazebrook, J., and Katagiri, F. 2009. Network properties of robust immunity in plants. PLoS Genet. 5:e1000772.

Van Ghelder, C., and Esmenjaud, D. 2016. TNL genes in peach: Insights into post-LRR domain. BMC Genomics 17:317.

Verlaan, M. G., Hutton, S. F., Ibrahem, R. M., Kormelink, R., Visser, R. G. F., Scott, J. W., Edwards, J. D., and Bai, Y. L. 2013. The Tomato yellow leaf curl virus resistance genes $T y-1$ and $T y-3$ are allelic and code for DFDGDClass RNA-dependent RNA polymerases. PLoS Genet. 9:e1003399.

Vieira, P., and Gleason, C. 2019. Plant-parasitic nematode effectors-Insights into their diversity and new tools for their identification. Curr. Opin. Plant Biol. 50:37-43.

Vos, P., Simons, G., Jesse, T., Wijbrandi, J., Heinen, L., Hogers, R., Frijters, A., Groenendijk, J., Diergaarde, P., Reijans, M., Fierens-Onstenk, J., de Both, M., Peleman, J., Liharska, T., Hontelez, J., and Zabeau, M. 1998. The tomato $\mathrm{Mi}-1$ gene confers resistance to both root-knot nematodes and potato aphids. Nat. Biotechnol. 16:1365-1369.

Wang, C. L., Bruening, G., and Williamson, V. M. 2009b. Determination of preferred $\mathrm{pH}$ for root-knot nematode aggregation using Pluronic F-127 gel. J. Chem. Ecol. 35:1242-1251.

Wang, C. L., Lower, S., and Williamson, V. M. 2009a. Application of Pluronic gel to the study of root-knot nematode behaviour. Nematology 11:453-464.

Williamson, V. M., and Roberts, P. A. 2009. Mechanisms and genetics of resistance. Pages 301-325in: Root-Knot Nematodes. M. Moens, R. N. Perry, and J. L. Starr, eds. CABI, Wallingford, U.K.

Wu, C. H., Abd-El-Haliem, A., Bozkurt, T. O., Belhaj, K., Terauchi, R., Vossen, J. H., and Kamoun, S. 2017. NLR network mediates immunity to diverse plant pathogens. Proc. Natl. Acad. Sci. USA 114:8113-8118.

Wubben, M. J. E., Su, H., Rodermel, S. R., and Baum, T. J. 2001. Susceptibility to the sugar beet cyst nematode is modulated by ethylene signal transduction in Arabidopsis thaliana. Mol. Plant-Microbe Interact. 14: 1206-1212.

Zhu, X., Xiao, K., Cui, H., and Hu, J. 2017. Overexpression of the Prunus sogdiana NBS-LRR subgroup gene PsoRPM2 promotes resistance to the root-knot nematode Meloidogyne incognita in tobacco. Front. Microbiol. 8: 2113. 